\title{
Physicomathematical Simulation Analysis for Small Bullets
}

\author{
D. N. Gkritzapis, ${ }^{, 1}$ N. E. Tsiatis, ${ }^{2}$ E E. Panagiotopoulos ${ }^{3}$ and D. P. Margaris ${ }^{4}$ \\ ${ }^{1}$ Physicist in Laboratory of Firearms and Tool Marks Section, Criminal Investigation Division \\ Captain of Hellenic Police, Hellenic Police, 11522 Athens, Lecturer in Hellenic Military Academy \\ and postgraduate Student in Mechanical Engineering and Aeronautics Dept., University of Patras, Hellas \\ ${ }^{2}$ Laboratory of Firearms and Tool Marks Section, Criminal Investigation Division, \\ Captain of Hellenic Police, Hellenic Police, 11522 Athens, Hellas \\ 3 postgraduate Student in Mechanical Engineering and Aeronautics Dept., \\ ${ }^{4}$ Professor in Mechanical Engineering and Aeronautics Dept., \\ Fluid Mechanics Laboratory, University of Patras, 26500 Patras, Hellas \\ Received 3 April 2008; Accepted 17 September 2008
}

\begin{abstract}
A full six degrees of freedom (6-DOF) flight dynamics model is proposed for the accurate prediction of short and long-range trajectories of small bullets via atmospheric flight to final impact point. The mathematical model is based on the full equations of motion set up in the no-roll body reference frame and is integrated numerically from given initial conditions at the firing site. The projectile maneuvering motion depends on the most significant force and moment variations, in addition to gravity and Magnus effect. The computational flight analysis takes into consideration the Mach number and total angle of attack effects by means of the variable aerodynamic coefficients. For the purposes of the present work, linear interpolation has been applied for aerodynamic coefficients from the official tabulated database. The developed computational method gives satisfactory agreement with published data of verified experiments and computational codes on atmospheric projectile trajectory analysis for various initial firing flight conditions.
\end{abstract}

\section{Nomenclature}

$\begin{array}{lll}C_{D} & =\end{array}$

$C_{L} \quad=$

$\begin{array}{ll}C_{L P} & = \\ C_{M Q} & =\end{array}$

$C_{M A} \quad=$

$C_{Y P A} \quad=$

$\mathrm{x}, \mathrm{y}, \mathrm{z}=$

$m$

$\mathrm{D}$

$\mathrm{S}$

$V \quad=$

$\widetilde{u}, \widetilde{v}, \widetilde{w}=$ projectile velocity components expressed in the no-rollframe, $\mathrm{m} / \mathrm{s}$

$\widetilde{p}, \widetilde{q}, \widetilde{r}=$ projectile roll, pitch and yaw rates in the moving frame,

drag force aerodynamic coefficient

lift force aerodynamic coefficient

roll damping moment aerodynamic coefficient

pitch damping moment aerodynamic coefficien

moment aerodynamic coefficient

projectile position coordinates in the inertial frame, $\mathrm{m}$

projectile mass, $\mathrm{kg}$

projectile reference diameter, $m$

dimensionless arc length

total aerodynamic velocity, $\mathrm{m} / \mathrm{s}$
respectively, $\mathrm{rad} / \mathrm{s}$
$=$ gravity acceleration, $\mathrm{m} / \mathrm{s}^{2}$
g

$\mathrm{I}$
$\mathrm{I}_{\mathrm{XX}}$
$\mathrm{I}_{\mathrm{YY}}$
$\mathrm{I}_{\mathrm{XX}}, \mathrm{I}_{\mathrm{YY}}, \mathrm{I}_{\mathrm{ZZ}}$
$\mathrm{I}_{\mathrm{XY}} \mathrm{I}_{\mathrm{YZ}} \mathrm{I}_{\mathrm{XZ}}$
$\mathrm{LE}_{\mathrm{MCM}}$
$\mathrm{LE}_{\mathrm{MCP}}$

$\rho$
$\varphi, \theta, \psi$
$\alpha, \beta$

Subscripts

o
$=$ projectile inertia matrix

$=$ projectile axial moment of inertia, $\mathrm{kg} \cdot \mathrm{m}^{2}$

$=$ projectile transverse moment of inertia about $\mathrm{y}$-axis through the center of mass, $\mathrm{kg} \cdot \mathrm{m}^{2}$

= diagonal components of the inertia matrix

$=$ off-diagonal components of the inertia matrix

$=$ distance from the center of mass (CG) to the Magnus center of pressure $(\mathrm{CM})$ along the station line, $\mathrm{m}$

$=$ distance from the center of mass $(\mathrm{CG})$ to the aerodynamic center of pressure (CP) along the station line, $\mathrm{m}$

$=$ density of air, $\mathrm{kg} / \mathrm{m}^{3}$

$=$ projectile roll, pitch and yaw angles, respectively, deg

$=$ aerodynamic angles of attack and sideslip, deg

\footnotetext{
* E-mail address: Hgritzap@yahoo.gr

ISSN: 1791-2377 @ 2008 Kavala Institute of Technology. All rights reserved.
} 


\section{Introduction}

Ballistics is the science that deals with the motion of projectiles. The word ballistics was derived from the Latin "ballista", which was an ancient machine designed to hurl a javelin. The modern science of exterior ballistics [1] has evolved as a specialized branch of the dynamics of rigid bodies, moving under the influence of gravitational and aerodynamic forces and moments. Exterior ballistics existed for centuries as an art before its first beginnings as a science. Although a number of sixteenth and seventeenth century European investigators contributed to the growing body of renaissance knowledge, Isaac Newton of England (1642-1727) was probably the greatest of the modern founders of exterior ballistics. Newton's laws of motion established, without which ballistics could not have advanced from an art to a science.

Pioneering English ballisticians Fowler, Gallop, Lock and Richmond [2] constructed the first rigid six-degree-of-freedom projectile exterior ballistic model.

The present work address a full six degrees of freedom (6DOF) projectile flight dynamics analysis for accurate prediction of short and long range trajectories of small bullets. The proposed flight dynamic model takes into consideration the influence of the most significant force and moment variations, in addition to gravity and Magnus effect. The applied aerodynamic coefficient analysis takes into consideration the variations depending on the Mach number flight and total angle of attack.

The efficiency of the developed method gives satisfactory results compared with published data of verified experiments and computational codes on dynamics model analysis of short and long-range trajectories of spin-stabilized projectiles and small bullets.

\section{Projectile Model}

The present analysis consider a 0.30 caliber $\left(0.308^{\prime \prime}\right.$ diameter $)$, 168 grain $(\approx 10.9$ gr) Sierra International bullet used by National Match M14 rifle is loaded into $7.62 \mathrm{~mm}$ M852 match ammunition for high power rifle competition shooting, as shown in Fig.1,2. The cartridge is intended and specifically prepared for used in those weapons designed as competitive rifles and for marksmanship training. This bullet is not for combat use. The cartridge case head stamping of MATCH identify the cartridge. It also has a knurl at the base of the cartridge case and a hollow point boat-tail bullet.

Basic physical and geometrical characteristics data of the above-mentioned $7.62 \mathrm{~mm}$ bullet illustrated briefly in Table 1 .

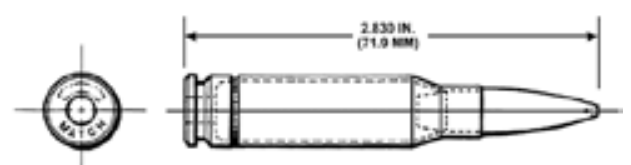

Fig. $17.62 \mathrm{~mm}$ bullet

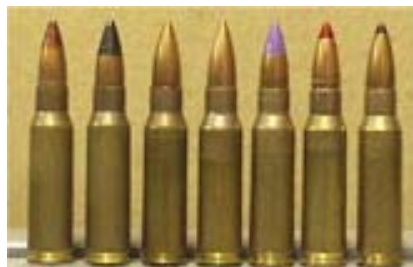

Fig. $27.62 \mathrm{~mm}$ match ammunition with a diameter of 0.30 caliber representative small bullet types.

\section{Table 1.}

Physical and geometrical data of $7.62 \mathrm{~mm}$ small bullet type.

\begin{tabular}{lc}
\hline \multicolumn{1}{c}{ Characteristics } & $\mathbf{7 . 6 2} \mathbf{~ m m ~ M 8 5 2}$ bullet \\
\hline Reference diameter, $\mathrm{mm}$ & 7.62 \\
Total length, $\mathrm{mm}$ & 71.88 \\
Total mass, $\mathrm{kg}$ & 0.385 \\
Axial moment of inertia, $\mathrm{kg} \cdot \mathrm{m}^{2}$ & $7.2282 \cdot 10^{-8}$ \\
Transverse moment of inertia, & $5.3787 \cdot 10^{-7}$ \\
$\mathrm{~kg} \cdot \mathrm{m}^{2}$ & \\
Center of gravity from the base, & 12.03 \\
$\mathrm{~mm}$ & \\
\hline
\end{tabular}

\section{Trajectory Flight Simulation Model}

A six degree of freedom rigid-projectile model [2], [3], [4], [5] has been employed in order to predict the "free" atmospheric trajectory to final target area without any control practices. The six degree of freedom flight analysis comprises the three translation components $(\mathrm{x}, \mathrm{y}, \mathrm{z})$ describing the position of the projectile's center of mass and three Euler angles $(\varphi, \theta, \psi)$ describing the orientation of the projectile body with respect to Fig.3.

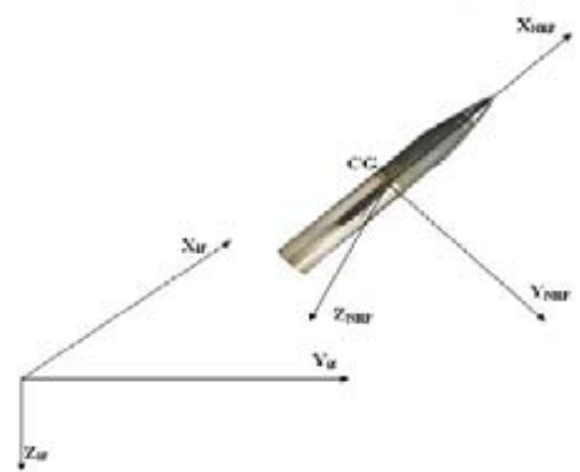

Fig 3. No-roll (moving) and fixed (inertial) coordinate systems for the projectile trajectory analysis.

Two main coordinate systems are used for the computational approach of the atmospheric flight motion. The one is a plane fixed (inertial frame) at the firing site. The other is a no-roll rotating coordinate system on the projectile body (no-roll-frame, NRF, $\varphi=0$ ) with the $X_{\mathrm{NRF}}$ axis along the projectile axis of symmetry and $\mathrm{Y}_{\mathrm{NRF}}, \mathrm{Z}_{\mathrm{NRF}}$ axes oriented so as to complete a right hand orthogonal system. 
Newton's laws of the motion state that the rate of change of linear momentum must equal the sum of all the externally applied forces and the rate of change of angular momentum must equal the sum of the externally applied moments, as shown respectively in the following forms:

$$
\begin{aligned}
& m \frac{d \vec{V}}{d t}=\vec{F}_{t o t} \\
& \frac{d \vec{H}}{d t}=\vec{M}_{t o t}
\end{aligned}
$$

where the total force acting on the projectile comprises the weight, the aerodynamic force and the Magnus force. Moreover, the total moment vector comprises the moment due to the standard aerodynamic force, the Magnus aerodynamic moment and the unsteady aerodynamic moment.

Therefore, the twelve state variables $\mathrm{x}, \mathrm{y}, \mathrm{z}, \varphi, \theta, \psi, \mathrm{u}, \mathrm{v}$, $\mathrm{w}, \mathrm{p}, \mathrm{q}$ and $\mathrm{r}$ are necessary to describe position, flight direction and velocity at every point of the projectile's atmospheric flight trajectory. Introducing the components of the acting forces and moments expressed in the no-roll-frame $(\sim)$ rotating coordinate system in Eqs $(1,2)$ with the dimensionless arc length $\mathrm{s}$ as an independent variable, the following full equations of motion for six-dimensional flight are derived:

$$
\begin{aligned}
& x^{\prime}=\frac{D}{V} \cos \psi \cos \theta \tilde{u}-\frac{D}{V} \sin \psi \tilde{v}+\tilde{w} \cos \psi \sin \theta \frac{D}{V} \\
& y^{\prime}=\frac{D}{V} \cos \theta \sin \psi \tilde{u}+\tilde{v} \cos \psi \frac{D}{V}+\tilde{w} \sin \theta \sin \psi \frac{D}{V} \\
& z^{\prime}=-\frac{D}{V} \sin \theta \tilde{u}+\frac{D}{V} \tilde{w} \cos \theta
\end{aligned}
$$

$\phi^{\prime}=\frac{D}{V} \widetilde{p}+\frac{D}{V} \tan \theta \widetilde{r}$

$\theta^{\prime}=\frac{D}{V} \widetilde{q}$

$\psi^{\prime}=\frac{D}{V \cos \theta} \widetilde{r}$

$$
\begin{aligned}
& \widetilde{u}^{\prime}=-\frac{D}{V} g \sin \theta-\frac{\pi}{8 m} \rho V D^{3} C_{D}-D^{3} \frac{\pi}{8 m} \rho V C_{D}^{2} \alpha^{2}- \\
& -D^{3} \frac{\pi}{8 m} \rho V C_{D}{ }^{2} \beta^{2}+\widetilde{v} \frac{D}{V} \widetilde{r}-\widetilde{q} \frac{D}{V} \widetilde{w}
\end{aligned}
$$$$
\widetilde{v}^{\prime}=-D^{3} \frac{\pi}{8 m} \rho\left(C_{L}+C_{D}\right) \widetilde{v}-\frac{D}{V} \widetilde{p} \widetilde{w} \tan \theta-\frac{D}{V} \widetilde{r} \widetilde{u}
$$

$\widetilde{w}^{\prime}=\frac{D}{V} g \cos \theta-D^{3} \frac{\pi}{8 m} \rho\left(C_{L}+C_{D}\right) \widetilde{w}+\frac{D}{V} \widetilde{q} \tilde{u}+\tan \theta \frac{D}{V} \tilde{p} \widetilde{v}$

$$
\widetilde{p}^{\prime}=D^{5} \frac{\pi}{16 I_{X X}} \tilde{p} \rho C_{L P}
$$

$$
\begin{aligned}
\widetilde{q}^{\prime} & =D^{3} \frac{\pi}{8 I_{Y Y}} \rho\left(C_{L}+C_{D}\right) \widetilde{w} L E_{M C P}+D^{4} \frac{\pi}{1 \sigma_{Y Y}} \rho C_{Y P A} \widetilde{p}\left(\frac{\widetilde{v}}{V}\right) L E_{M C M^{+}} \\
& +D^{5} \frac{\pi}{1 \sigma_{Y Y}} \rho C_{M Q^{-}}+D^{4} \frac{\pi}{8 I_{Y Y}} \rho C_{M A^{-}}-\frac{D}{V} \widetilde{r} \frac{I_{X X}}{I_{Y Y}} \widetilde{p}-\frac{D}{V} \widetilde{r}^{2} \tan \theta
\end{aligned}
$$

$$
\begin{aligned}
\widetilde{r}^{\prime}= & -D^{3} \frac{\pi}{8 I_{Y Y}} \rho\left(C_{L}+C_{D}\right) \widetilde{v} L E_{M C P}+D^{4} \frac{\pi}{16 I_{Y Y}} \widetilde{p} \rho C_{Y P A}\left(\frac{\widetilde{w}}{V}\right) L E_{M C M^{+}} \\
& +D^{5} \frac{\pi}{16 I_{Y Y}} \rho C_{M Q} \widetilde{r}-D^{4} \frac{\pi}{8 I_{Y Y}} \rho C_{M A}+\frac{D}{V} \widetilde{p} \widetilde{I_{X X}} I_{Y Y}+\frac{D}{V} \widetilde{q} \widetilde{r} \tan \theta
\end{aligned}
$$

The projectile dynamics trajectory model consists of twelve highly first order ordinary differential equations, which are solved simultaneously by resorting to numerical integration using a 4th order Runge-Kutta method. In these equations, the following sets of simplifications are employed: velocity $\tilde{u}$ replaced by the total velocity $V$ because the side velocities $\widetilde{v}$ and $\widetilde{w}$ are small. The aerodynamic angles of attack $\alpha$ and sideslip $\beta$ are small for the main part of the atmospheric trajectory $\alpha \approx \widetilde{w} / V, \beta \approx \widetilde{v} / V$, the projectile is geometrically symmetrical $\mathrm{I}_{\mathrm{XY}}=\mathrm{I}_{\mathrm{YZ}}=\mathrm{I}_{\mathrm{XZ}}=0, \mathrm{I}_{\mathrm{YY}}=\mathrm{I}_{\mathrm{ZZ}}$ and aerodynamically symmetric. With the aforementioned assumptions, the expressions of the distance from the center of mass to the standard aerodynamic and Magnus centers of pressure are simplified.

\section{Initial Spin Rate Estimation}

In order to have a statically stable flight projectile trajectory motion, the initial spin rate $\tilde{p}_{0}$ prediction at the gun muzzle in the firing site us important. According to McCoy definitions [1], the following form is used:

$$
\tilde{p}_{0}=2 \pi V_{0} / \eta D(\mathrm{rad} / \mathrm{s})
$$

where $V_{o}$ is the initial firing velocity $(\mathrm{m} / \mathrm{s}), \eta$ the rifling twist rate at the gun muzzle (calibers per turn), and $\mathrm{D}$ the reference diameter of the projectile type (m). Typical values of rifling twist $\eta$ are $1 / 18$ calibers per turn for big projectile and 12 inches per turn for small bullet, respectively.

\section{Computational Simulation}

The flight dynamic model of $7.62 \mathrm{~mm}$ bullet involves the solution of the set of the twelve nonlinear first order ordinary differentials, Eqs (3-14), which are solved simultaneously by resorting to numerical integration using a 4th order RungeKutta method, and regard to the 6-D nominal atmospheric projectile flight. 
The constant [7], [8] dynamic flight model uses mean values of the experimental aerodynamic coefficients variations [1] (see table 2).

Table 2

Trajectory aerodynamic parameters of atmospheric flight dynamic model

$\frac{7.62 \mathrm{~mm} \text { with constant aerodynamic coefficients }}{C_{D}=0.235, C_{L}=2.205, C_{L P}=-0.01}$
$C_{M Q}=-4.700, C_{M A}=2.92, C_{Y P A}=-1.26$

The results give the computational simulation of the 6-D non-thrusting and non-constrained flight trajectory path for some specific big projectiles and small bullets types. Initial flight conditions for the dynamic flight simulation model with constant and variable aerodynamic coefficients are illustrated in Table 3 for the examined test case.

Table 3.

Initial flight parameters of the projectile examined test cases.

\begin{tabular}{c|c}
\hline Initial flight data & $\mathbf{7 . 6 2} \mathbf{~ m m}$ bullet \\
\hline $\mathrm{x}, \mathrm{m}$ & 0.0 \\
$\mathrm{y}, \mathrm{m}$ & 0.0 \\
$\mathrm{z}, \mathrm{m}$ & 0.0 \\
$\varphi, \mathrm{deg}$ & 0.0 \\
$\theta, \mathrm{deg}$ & $1^{\circ}, 7^{\circ}$ and $15^{\circ}$ \\
$\psi, \mathrm{deg}$ & 2.0 \\
$\mathrm{u}, \mathrm{m} / \mathrm{s}$ & 792.48 \\
$\mathrm{v}, \mathrm{m} / \mathrm{s}$ & 0.0 \\
$\mathrm{w}, \mathrm{m} / \mathrm{s}$ & 0.0 \\
$\mathrm{p}, \mathrm{rad} / \mathrm{s}$ & $16,335.0$ \\
$\mathrm{q}, \mathrm{rad} / \mathrm{s}$ & 0.0 \\
$\mathrm{r}, \mathrm{rad} / \mathrm{s}$ & 0.0 \\
\hline
\end{tabular}

\section{Results and Discussion}

The flight path trajectories of the present dynamic model with initial firing velocity of $793 \mathrm{~m} / \mathrm{sec}$ and rifling twist 12 inches per turn at initial pitch angles of $1^{\circ}, 7^{\circ}$ and $15^{\circ}$ are indicated in Figure 4 for two cases: constant ${ }^{7}$ and variable ${ }^{8}$ aerodynamic coefficients. The small bullet is examined for its atmospheric constant flight trajectories predictions in Fig. 4, fired at no wind sea-level conditions at $1^{\circ}$ gives a range to impact at 1,190 $\mathrm{m}$ with a maximum height at almost $6.7 \mathrm{~m}$. At $7^{\circ}$, the predicted level-ground range is approximately $2,778 \mathrm{~m}$ and the height is $150 \mathrm{~m}$, and at 15 degrees the impact point and the height are $3,410 \mathrm{~m}$ and $440 \mathrm{~m}$, respectively.

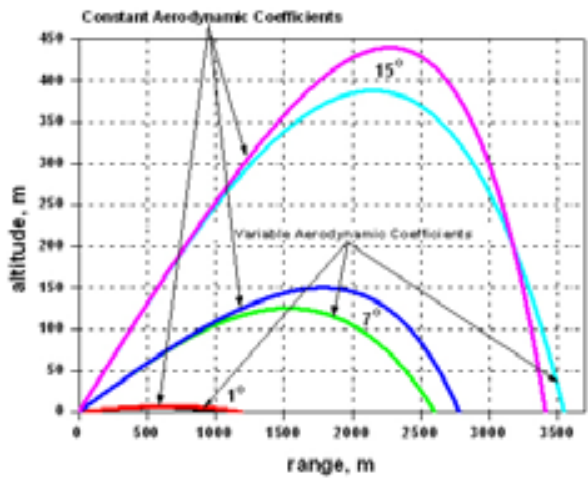

Fig 4. Impact points and flight path trajectories with constant and variable aerodynamic coefficients for $7.62 \mathrm{~mm}$ bullet at low and high quadrant elevation angles of $1^{\circ}, 7^{\circ}$, and $15^{\circ}$.

The same figure shows the trajectory flight path of 7.62 $\mathrm{mm}$ bullet with variable aerodynamic coefficients, and at $1^{\circ}$ pitch angle gives range almost $1 \mathrm{~km}$ with height $6 \mathrm{~m}$, at 7 degrees gives impact point 2,600 $\mathrm{m}$ and height $125 \mathrm{~m}$ and at 15 degrees the range and the height are $3,545 \mathrm{~m}$ and $388 \mathrm{~m}$, respectively. There is big difference with the flight path trajectory with constant aerodynamic coefficients.

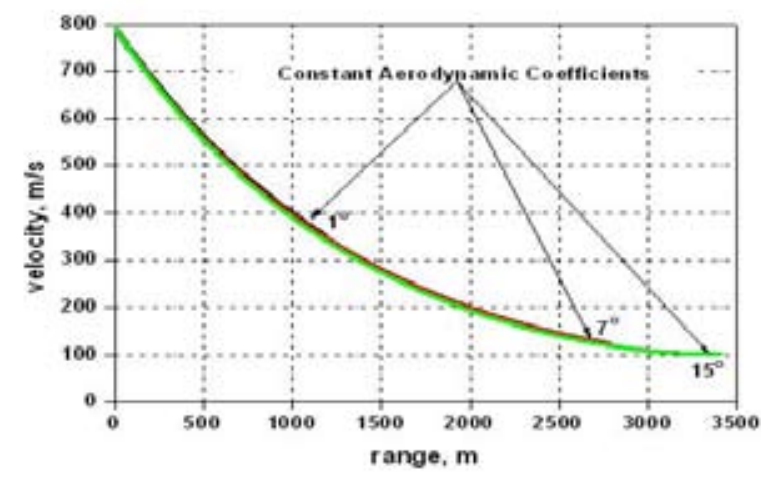

Fig 6. Velocity versus range with constant aerodynamic coefficients for $105 \mathrm{~mm}$ projectile.

Furthermore, the computational results for $7.62 \mathrm{~mm}$ bullet flight path with constant and variable aerodynamic coefficients at elevation angles of $1^{\circ}, 7^{\circ}$ and $15^{\circ}$ are illustrated in Fig. 5 and 6. At pitch angle of 1 degree, the velocity for the flight path with constant aerodynamic coefficients decreases to the values of almost $350 \mathrm{~m} / \mathrm{sec}$ and $300 \mathrm{~m} / \mathrm{sec}$ with variable aerodynamic coefficients. At pitch angle of 7 degrees, the velocity decreases to the values of almost 124 and $169 \mathrm{~m} / \mathrm{sec}$. Moreover, at pitch angle of 15 degrees the velocity decreases to values of 101 and $132 \mathrm{~m} / \mathrm{sec}$, respectively. 


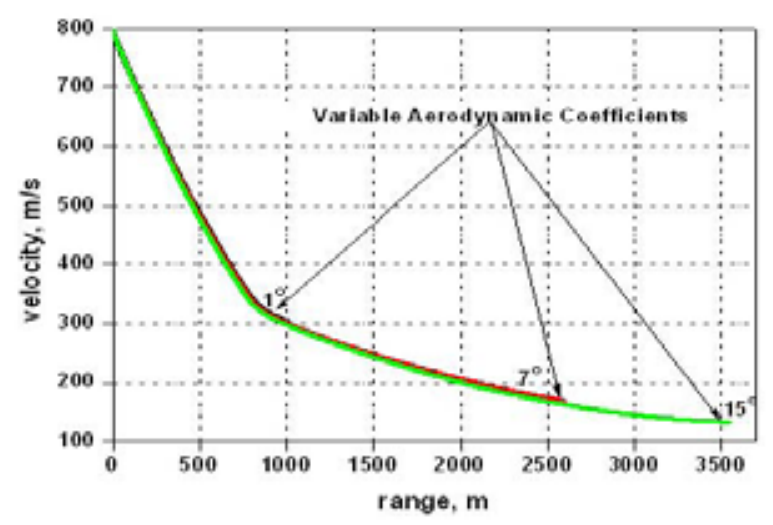

Fig 7. Velocity versus range of $7.62 \mathrm{~mm}$ M852 bullet at initial elevation angles of $1^{\circ}, 7^{\circ}$ and $15^{\circ}$

Figure 8 shows the time of the flight trajectory with constant and variable coefficients, at sea level with no-wind for $7.62 \mathrm{~mm}$ bullet at elevation angles $1^{\circ}, 7^{\circ}$ and $15^{\circ}$. The bullet with initial firing velocity of $793 \mathrm{~m} / \mathrm{s}$, gives values of time 2,3 sec, 9,5 sec and $17 \mathrm{sec}$, respectively.

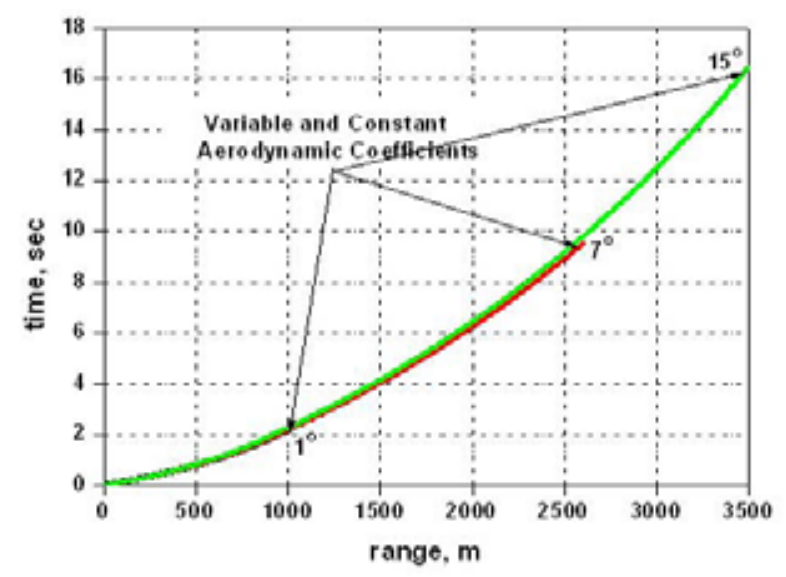

Fig 8. Time path trajectories at elevation angles of 1, 7 and 15 degrees, for $7.62 \mathrm{~mm}$ bullet with variable and constant aerodynamic coefficients.
Moreover, from the results of the presented applied method with variable constant aerodynamic coefficients, at $1^{\circ}, 7^{\circ}$ and $15^{\circ}$ pitch angles, the roll rate decreases to the values 14,620 $\mathrm{rad} / \mathrm{s}, 11,626 \mathrm{rad} / \mathrm{s}$ and 10,583 $\mathrm{rad} / \mathrm{s}$, respectively.( Fig. 9)

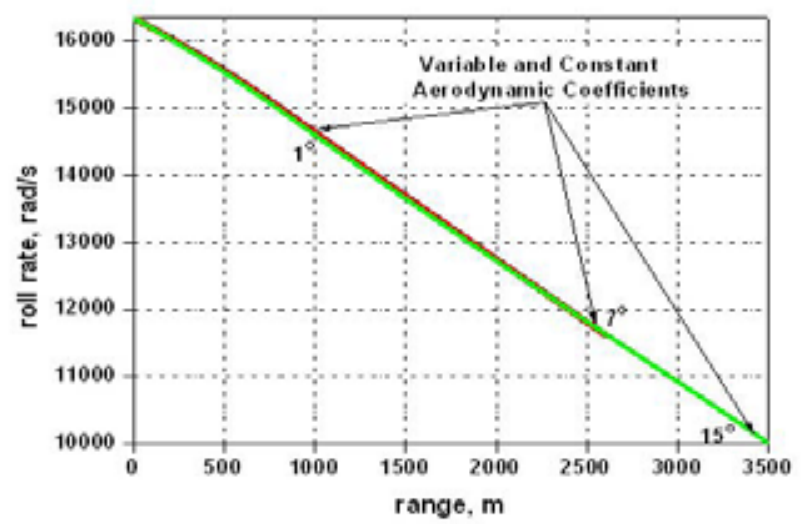

Fig 9. Roll rate versus range at elevation angles of 1, 7 and 15 degrees, for $7.62 \mathrm{~mm}$ bullet with variable and constant aerodynamic coefficients.

\section{Conclusion}

The complicated six degrees of freedom (6-DOF) simulation flight dynamics model is applied for the accurate prediction of short and long-range trajectories results for small bullets. It takes into consideration the Mach number and the total angle of attack variation effects by means of the variable and constant aerodynamic coefficients. The computational results of the proposed synthesized analysis are in good agreement compared with other technical data and recognized exterior atmospheric projectile flight computational models.

\section{References}

1. McCoy, R., Modern Exterior Ballistics, Schiffer, Attlen, PA, 1999, pp.165-183, 217-218, 244, 248.

2. Fowler, R., Gallop, E., Lock, C., and Richmond H., "The Aerodynamics of Spinning Shell," Philosophical Transactions of the Royal Society of London, Series A: Mathematical and Physical Sciences, Vol. 221, 1920.

3. Hainz, L., and Costello, M., "Modified Projectile Linear Theory for Rapid Trajectory Prediction," Journal of Guidance, Control, and Dynamics, Vol.28, No. 5, 2005, pp.1007-1009.

4. Etkin, B., Dynamics of Atmospheric Flight, John Wiley and Sons, New York, 1972

5. Amoruso, M. J., "Euler Angles and Quaternions in Six Degree of Freedom Simulations of Projectiles," Technical Note, 1996.
6. Costello, M., and Anderson, D., "Effect of Internal Mass Unbalance on the Terminal Accuracy and Stability of a projectile," AIAA Paper, 1996.

7. Gkritzapis, D., N., Panagiotopoulos, E. E., Margaris, D. P., Papanikas, D. G.: "Atmospheric Flight Dynamic Simulation Modelling of Spin-Stabilized Projectiles”, Proceedings of the 2nd International Conference on Experiments / Process / System Modelling / Simulation / Optimization, 2nd IC-EpsMsO, 4-7 July 2007, Athens, Greece.

8. Gkritzapis, D. N., Panagiotopoulos, E. E., Margaris, D. P., Papanikas, D. G.: "Computational Atmospheric Trajectory Simulation Analysis of Spin-Stabilized Projectiles and Small Bullets”, Atmospheric Flight Mechanics Conference and Exhibit, AIAA Paper 2007-6584, 20-23 August 2007, Hilton Head, South Carolina. 